\title{
Artificial Intelligence-Based Strategies for Improving the Teaching Effect of Art Major Courses in Colleges
}

\author{
https://doi.org/10.3991/ijet.v15i22.18199 \\ Ran Yang \\ Sichuan Conservatory of Music, Chengdu, China \\ yangjinhan000@163.com
}

\begin{abstract}
In the context of artificial intelligence (AI), this paper attempts to develop strategies to improve the teaching effect of art major courses in colleges, and overcome the existing problems with the improvement process. Firstly, the authors analyzed the manifestations of the teaching effects of art major courses, and then discussed the relevant factors that affect the teaching effect of such courses. Next, the potential improving effects of the AI on the teaching effect of art major courses were expounded in details. On this basis, an evaluation model was developed to reflect the improving effects. Finally, several AI-based strategies were put forward to optimize the teaching of art major courses in collages. This research fully integrates theoretical analysis with model calculation, and innovatively introduces the AI to the teaching effect improvement in major courses.
\end{abstract}

Keywords-Teaching effect, major courses, art, colleges, artificial intelligence (AI)

\section{Introduction}

Following its rapid development, the AI technology has been applied in the field of higher education more widely and deeply. It has an increasingly close relationship with the improvement of the higher education, and plays an important role in promoting the teaching effect in higher education [1-4]. As an important part of higher education, art education provides an indispensable support for the cultivation of art professional talents. It's the key to the cultivation of art professionals on how to improve the teaching effect of art major courses, especially in the context of the AI [5-8]. To this end, some researchers have carried out a series of studies. For example, Yu [9] explored the way of improving the teaching effect of art major courses based on micro-courses and the corresponding path, providing certain references to the teaching innovation of art major. Lin [10] analyzed the current development status of art elective courses in colleges, and discussed the optimization strategies of art major courses. Taking space composition and design as an example, Wan [11] analyzed the promotion effect of new media digital imaging technology on the teaching and learning of environmental art design. Chen [12] studied the effect of micro-course teaching in the teaching process of art courses in higher vocational education. Besgen et al. [13] discussed and analyzed the 
teaching strategies of art and basic design education, which provided a good reference for the teaching of art major courses. Besgen [14] explained in detail the common elements and principles in painting and architecture by examples, and emphasized the importance of the relationship between the two, aimed at proposing a new teaching and learning strategy for basic design education.

The above research provides a good reference for improving the teaching effect of art major courses. The implementation of art courses is a complex system engineering. Especially with the continuous development of society and the application of artificial intelligence technology, there emerge some new problems due to the existence of various influencing factors. Also, the existing solutions and measures often have certain limitations. For this, the authors conducted further research on the improvement of the teaching effect of art major courses in colleges in the context of the AI technology, and constructs a corresponding evaluation model based on the AHP [15-16] and gray system theory [17-18]. This paper consists of 7 parts. The first part introduces and analyses the current research issues on the improvement of teaching effects in the context of AI; the second part discusses the manifestation of the teaching effect of art courses; the third part analyzes the factors affecting the teaching effect; the fourth part elaborates on the promotion effect of AI technology on the improvement of art major courses; the fifth part presents an evaluation model for this; the sixth part proposes the AI-based strategies to improve the teaching effect of art courses; the seventh part gives the research conclusion.

\section{The Manifestation of the Teaching Effect of Art Major Courses}

The teaching effect of art majors needs to reflect the professionalism, typicality, epochal character, and expansibility. It is necessary to focus on the coordination and unity in the quality and quantity of the teaching content, and effectively improving the quality of art professional talent training from multi-dimensions and multi-perspectives, thereby promoting the comprehensive quality of art professionals.

\subsection{The professionalism of art major course teaching:}

Different from the general courses, the art major course focuses on the systematical teaching and transfer of the art professional knowledge, and the expansion of the art professional knowledge in a more deep and broad manner, thus effectively improving the comprehensive quality of art professionals. To reflect the professionalism of the art major teaching, it is necessary to do a good job in the following aspects. The first is the division of the art majors. From the perspective of disciplines, art includes many art majors, and different majors often have different requirements for teaching content. Therefore, it is of great significance to divide these majors scientifically and then formulate reasonable teaching goals and content. The second is to well plan the teaching content of art majors. For a specific art major, the teaching content involved is often very broad. The organization of the teaching content, planning of the teaching 
knowledge points, and implementation of the teaching plan etc., will directly affect the teaching effect of art major courses. The third is the classification of the teaching content of art major courses. For the training of art professional talents, it is necessary to cultivate art professional skills while imparting the art professional knowledge, i.e., besides theoretical knowledge of art professional courses, the training of art talents often requires a lot of practical exercises to improve the comprehensive quality of art professionals through the integration of art professional practice and theory.

\subsection{The typicality of art major course teaching}

The teaching types, forms and content of art major courses have diversity. As more and more art major knowledge and teaching content to be taught are required over time, it has become more complicated to fully teach and transfer the accumulated knowledge of various forms and categories of art within a period of time. For this reason, it is necessary to select typical teaching content, types, and methods, etc. during the teaching of art majors, and achieve the systematic teaching. The author believes that the typicality of art major course teaching includes the following aspects. The first is the typicality of the teaching content of art major courses, that is, selecting the teaching content that is suitable for the cultivation of art talents; the second is the typicality of teaching materials, that is, selecting the high-quality textbooks that are suitable for the cultivation of art professionals, especially the formation of art professional courses in the context of artificial intelligence; the third is the typicality of the teaching form, which is suitable for the cultivation of art professionals based on the AI; the fourth is the typicality of the teaching categories, that is, select the teaching mode that is suitable for the cultivation of art professionals under the background of artificial intelligence, and focus on the integration of practical and theoretical teaching.

\subsection{The epochal character of art major course teaching}

The pursuit of art often varies in different times. Especially following the continuous progress of the times, the form, content, and connotation of art have been undergoing constant changes, and the demands for art majors and art professional talents in society are also increasing. This endows the cultivation of art professionals with obvious epochal character; especially as the AI technology is applied in education more deeply, the demands for teaching reforms of art course in the modern education have become more urgent in many aspects such as teaching forms, means, content, and methods. The author believes that the epochal character that the teaching of art majors should conform to the current social development and integrate the development of art into the current social needs. Thus, it is necessary to manifest the application effect of AI-based art major course in all aspects of art course teaching such as teaching forms, means, content, and methods. 


\subsection{The expansibility of art major course teaching}

Art comes from the society, and serves it. The development of art is closely related to social activities. From the perspective of development, human society is constantly developing. Especially with the rapid development of modern science and technology, the AI technology plays an increasingly important role in the progress of modern society, and is also more and more widely used in various engineering fields of social development. The in-depth application and development of AI technology in the education field has effectively promoted the teaching efficiency and quality of art major courses, and improved the cultivation of art professionals. And due to the in-depth development of the AI technology, its application in the field of education will also deepen, which will be more conducive to promoting the integration of art and social activities, so that art can better serve the society. Therefore, the author believes that the teaching of art majors based on the AI should pay more attention to the expansibility of art majors as well as the integration of art major teaching and social needs.

\section{Factors Affecting the Teaching Effect of Art Majors}

\subsection{The teacher resources of art major courses}

The teaching resource of art major courses is a key factor affecting the teaching effect and a basic factor in the implementation of art major courses. It includes many aspects, such as the construction of curriculum teaching team, the investment of curriculum teaching funds, the hardware configuration, and the professional quality of curriculum teachers for art majors. It can be seen that in the teaching resource construction of art major course, the rationality of organizational structure and talent echelon, the adequacy of fund investment, the completeness of the hardware configuration, and the high professional quality of the curriculum teachers are conductive to the improvement of the teaching effect of art major courses; otherwise, the teaching effect of art major courses will be affected to a certain extent, or even seriously. In particular, the qualityoriented education in the context of AI has an even more urgent need for high-level major resources.

\subsection{Teaching model of art major courses}

Due to the continuous in-depth application and development of AI technology in the field of education, modern teaching models have undergone great changes in the teaching content, means, methods, and forms. The teaching content of traditional art major courses is often only in paper version, and the art major course is usually only taught using the blackboard. The teaching means is relatively simple and inefficient. Also, the traditional teaching methods and forms of art major courses are only a single teaching method of lecture. Due to the lack of effective intelligent technical support, it is difficult to effectively implement the demonstration teaching, the inquiry teaching, and the independent learning teaching. With the development of the AI technology, the teaching 
content of modern art major courses has begun to be integrated into the electronic version, so that the teaching content is more formal and intuitive, and the knowledge content of teaching content is also showing an order of magnitude increase. Based on the AI technology, modern art major course teaching is supported by a variety of intelligent methods, such as Multimedia classrooms, computer centers, and online learning platforms, which has diversified teaching methods for art majors and effectively improved teaching efficiency. Besides, the AI development has resulted in a more advanced teaching methods and forms for art major courses, which plays an important role in the improvement of the teaching effect of art major courses.

\subsection{Application of intelligence education technology}

In the modern quality-oriented education, the school's goal of training art talents focuses on the improvement of students' comprehensive ability, and the integration between art students' professional quality and intelligent technology development. With the continuous deepening of AI technology in art professional education, the integration of art and AI has become more and more close, and the art major has become more intelligent zed. Moreover, the continuous development of intelligent technology, such as the virtual reality technology, Internet technology, information technology, multimedia technology, etc. has made the content of modern art major courses complicated, and multiplied the knowledge points of professional courses. It is the key point of concern on how to effectively teach the art major courses. Thus, the scientific and reasonable integration of modern AI technology into the teaching process of art major courses will not only enrich the teaching content, but also effectively improve the adaptability of art major courses. This is of great significance to the improvement of the teaching effect of art major courses.

\subsection{Teaching management of art major course}

The smooth implementation of art major course teaching requires the relatively complete professional curriculum teaching management rules and systems, which play a very necessary role in guiding the progress of art professional curriculum teaching. The teaching management of art majors needs to be performed well from different aspects such as the formulation of the teaching management system and teaching objectives, the planning of teaching plans and syllabuses, the planning of teaching organization structure, the compilation and planning of teaching materials, implementation plan of teaching tasks, and student management system etc. A sound teaching management system and student management system, clear teaching goals, scientific and reasonable teaching plans and syllabuses, teaching task planning, complete teaching organization structure, and classic quality professional course materials are essential for the promotion of the teaching effect of art major course. 


\subsection{Assessment and feedback of art major course teaching}

The teaching of art major course is a relatively complex project. In the teaching process of art majors, it is necessary to comprehensively consider internal, external, individual, and overall influencing factors, and to constantly track, supervise, assess, and feedback the teaching process of art majors. Also, some unknown problems will inevitably arise in this process, especially with the emergence and application of new AI technologies. It's necessary to deal with these problems and influencing factors in combination with the teaching objectives, tasks, and teaching planning of art majors, further effectively improve the teaching effect, teaching quality of art majors, and promotes the learning efficiency of students. For this, the assessment and feedback mechanism of art major course teaching based on AI need to be considered.

\section{The Improving Effect of AI Technology on the Teaching Effect of Art Major Courses}

The author believes that the AI technology plays a very important role in promoting the teaching effect of art major courses, which is reflected in the following aspects.

\subsection{Enriching the teaching content of art major courses}

The AI technology is conductive to the rapid accumulation of the teaching content, and diversifies the presentation forms of the teaching content in art major. Compared with the traditional teaching content in paper form, the electronic forms such as texts, pictures, audios, videos, etc. become more popular under the support of AI technology. Moreover, with the development of intelligent technology, the electronic storage of the teaching content of art majors has become more and more convenient. Not only the storage of the teaching content has a larger capacity, but also the query, acquisition and summary are more convenient, which enriches the teaching content of art major courses, and is more conducive to students' receiving a wealth of professional knowledge, thereby expanding students' professional perspectives to a greater extent.

\subsection{Diversifying the teaching means and forms of art major courses}

In the context of the AI technology, the teaching of art major no longer relies on traditional classrooms and blackboards. It can use a variety of AI-based teaching means and forms such as digital classrooms, multimedia classrooms, information centers, and multifunctional teaching and research rooms in the education field. The teaching means of art major courses become more digital and intelligent. In addition, a series of new teaching forms and platforms have emerged, such as micro-courses, MOOCs, flipped classrooms, rain classrooms, and cloud classrooms, etc., which diversifies the teaching means and forms of art major courses, and improves the teaching effects. 


\subsection{Improving the ability to share teaching information for art major courses}

Following the continuous development and application of AI technology, the network teaching platforms for art major courses have had more course teaching functions, and better performance. Through the standardizing and processing of the course teaching content in the relevant teaching platform, on the one hand, the teaching content of art major courses can be better for teaching management, on the other hand, it can be inquired and used more easily, maximizing the use of teaching content of art major courses, and promoting the exchange and learning of knowledge.

\subsection{Enhancing the teaching exchange and feedback of major courses}

The AI technology helps to not only realize the construction of network teaching platforms for art major courses, but also establish a professional exchange and feedback platform. Through the construction and application of related intelligent platforms, it is possible to effectively supervise the teaching content of art majors, intelligently manage the implementation of teaching tasks and the development of teaching progress, and also provide a channel for the communication between teachers, between teachers and students, between teachers and administrators, and between students. In this channel, teachers can observe the learning status of students in time, students can quickly feedback personal learning situations and problems, and administrators can effectively view the teaching status, thereby building an intelligent learning communication bridge for teachers, students, and administrators. This is more conducive to the implementation of the teaching process.

\subsection{Expanding the teaching scope and perspective of major course teaching}

As above, the application of AI technology in the field of education enriches the teaching content of art majors, diversifies the teaching means and forms, and improves the sharing, communication and feedback of information, which makes it easier for art teachers and students to absorb professional knowledge, and to access the cutting-edge art information. Furthermore, this rapidly increases the professional knowledge of art teachers and students, and improves their ability to recognize and understand art professional knowledge, thereby expanding the teaching scope and perspective of art major course.

\section{Evaluation Model for Improving the Teaching Effect of Art Major Courses}

From the above, the teaching effect of art majors in the context of AI is affected by many factors. To effectively analyze the teaching effect of art majors, it is necessary to establish an improved evaluation model. 


\subsection{Evaluation indicators for improving the teaching effect of art major courses}

Through the analysis above, the authors analyzed the improvement of the teaching effect of art major courses under the background of the AI from three dimensions, namely, the teaching management, the teaching implementation, and the teaching output.

First, from the dimension of teaching management, it mainly assesses the basic guarantee ability of art major course teaching, and its evaluation indicators include teaching fund investment of major course, teaching talent echelon construction, teacher professional ability training, the construction of professional course teaching software and hardware facilities, the completeness of the teaching management system, and the perfection of the teaching assessment system. Second, the analysis from the dimensions of the implementation mainly focuses on assessing the execution ability of art major courses. The related evaluation indicators need to be analyzed comprehensively from the aspects of the scientificity of professional curriculum teaching plan, the rationality of the syllabus formulation, the orderly implementation of teaching tasks, systematisms of teaching content, the innovation of teaching methods, the advancement of teaching methods, the diversity of teaching forms, the uprightness of teaching attitudes, the interaction of classroom teaching, and the completion of teaching goals. Thirdly, from the dimensions of the teaching output, it mainly evaluates the specific results produced by the teaching of art major courses. The evaluation indicators need to include the qualification rate of students, the rate of excellence, the number of student awards, the mastery of students' professional skills, social satisfaction, independent learning ability training, and innovation ability training etc.

\subsection{Weighting of evaluation indicators}

To effectively analyze the contribution of different evaluation indicators to the evaluation results, this paper uses the AHP [19-21] method to weight the evaluation indicators. The specific implementation steps are as follows.

First, invite the domain experts to score the evaluation indicators on a 1-9 ratio scale, and establish the corresponding evaluation matrix B, namely

$$
\mathbf{B}=\left[\begin{array}{ccccc}
b_{11} & \cdots & b_{1 i} & \cdots & b_{1 n} \\
\vdots & \vdots & \vdots & \vdots & \vdots \\
b_{i 1} & \cdots & b_{i i} & \cdots & b_{i n} \\
\vdots & \vdots & \vdots & \vdots & \vdots \\
b_{n 1} & \cdots & b_{n i} & \cdots & b_{n n}
\end{array}\right]=\left[b_{i j}\right]_{n x n}
$$

where, $n$ is the number of evaluation indicators, $b_{i j}$ is the importance of the evaluation indicators relative to the evaluation indicators, and satisfies $b_{i j}=1 / b_{j i}$. 
Secondly, calculate and analyze the weights of the evaluation indicators for the improvement of the teaching effect of art major courses. The weight of the $i$-th evaluation indicator is $w_{i}$, namely:

$$
w_{i}=\sum_{j=1}^{n}\left(b_{i j} / \sum_{i=1}^{n} b_{i j}\right) / \sum_{i=1}^{n} \sum_{j=1}^{n}\left(b_{i j} / \sum_{i=1}^{n} b_{i j}\right)
$$

Then, obtain the evaluation index weight sequence $W$ for the improvement of the teaching effect:

$$
W=\left(w_{1}, \cdots, w_{i}, \cdots, w_{n}\right)^{T}
$$

Finally, perform consistency test analysis on the evaluation matrix $\mathbf{B}$.

$$
\left\{\begin{array}{l}
C I=\left(\lambda_{\max }-n\right) /(n-1) \\
\lambda_{\max }=\frac{1}{n} \sum_{i=1}^{n} \frac{(\mathbf{B} * W)_{i}}{w_{i}} \\
C R=C I / R I
\end{array}\right.
$$

Among them, $R I$ represents the random consistency index value, which can be selected from the random consistency index value table according to the value of $n$.

If satisfying $C R<0.1$, it means that the weight sequence obtained above is valid; otherwise, the evaluation matrix $\mathbf{B}$ needs to be modified to meet the consistency test requirements.

\subsection{The realization of grey cluster analysis model}

In order to grade the teaching effect of art major courses, the authors adopted the grey cluster analysis method [22-25]. If the initial value of the $i$-th evaluation index for the object to be evaluated is $v_{i}(P)$, and the section domain of the $i$-th evaluation index is $v_{i}(G)=\left[v_{i}^{a}(G), v_{i}^{b}(G)\right], v_{i}^{a}(G) \leq v_{i}^{b}(G)$. When the $i$-th evaluation indicator is a benefit index, its standardized value $u_{i}(P)$ is given as:

$$
u_{i}(P)=\left(v_{i}(P)-v_{i}^{a}(G)\right) /\left(v_{i}^{b}(G)-v_{i}^{a}(G)\right)
$$

When it is a cost index, its standardized value $u_{i}(P)$ is given as:

$$
u_{i}(P)=\left(v_{i}^{b}(G)-v_{i}(P)\right) /\left(v_{i}^{b}(G)-v_{i}^{a}(G)\right)
$$

To evaluate the teaching effect of art major courses, the gray classes of the teaching effect evaluation were divided into $m$; the larger the gray class value, the better the 
teaching effect. According to the grey system theory, the whitening weight function of the teaching effect evaluation can be constructed in three forms. The first form is the whitening weight function of the upper limit measure, and the gray class 1 is generally expressed in this form:

$$
\psi_{i}^{1}(u)=\psi_{i}^{1}\left[u_{a}, u_{b},-,-\right]= \begin{cases}0 & u \notin\left[0, u_{d}\right] \\ \frac{u_{d}-u}{u_{d}-u_{c}} & u \in\left[u_{c}, u_{d}\right] \\ 1 & u \in\left[0, u_{c}\right]\end{cases}
$$

where, $u_{c}$ and $u_{d}$ are the function inflection points of the gray class.

The second form is the whitening weight function of lower limit measure, and the gray class $m$ is generally expressed in this form:

$$
\psi_{i}^{m}(u)=\psi_{i}^{m}\left[-,-, u_{c}, u_{d}\right]= \begin{cases}0 & u \leq u_{a} \\ \frac{u-u_{a}}{u_{b}-u_{a}} & u \in\left[u_{a}, u_{b}\right] \\ 1 & u \geq u_{b}\end{cases}
$$

where, $u_{a}$ and $u_{b}$ are the function inflection points of the gray class, $0 \leq u_{a} \leq u_{b} \leq 1$.

The third form is the whitening weight function of moderate measure, and the gray class $k \mid 2 \leq k \leq(m-1)$ is generally expressed in this form:

$$
\psi_{i}^{k}(u)=\psi_{i}^{k}\left[u_{a}, u_{b},-, u_{d}\right]=\left\{\begin{array}{lc}
\frac{u-u_{a}}{u_{b}-u_{a}} & u \in\left[u_{a}, u_{b}\right] \\
0 & u \notin\left[u_{a}, u_{d}\right] \\
1 & u=u_{b} \\
\frac{u_{d}-u}{u_{d}-u_{b}} & u \in\left[u_{b}, u_{d}\right]
\end{array}\right.
$$

where, $u_{a}, u_{b}$ and $u_{d}$ are the function inflection points of the gray class, $0 \leq u_{a} \leq u_{b} \leq$ $u_{d} \leq 1$.

Thus, on the basis of obtaining the normalized value $u_{i}(P)$ of the $i$-th evaluation index for the object $P$ to be evaluated for the teaching effect of art majors, we derived the value of the whitening weight function $\psi_{i}^{j}\left(u_{i}(P)\right)$ between this value and the $j$-th gray class. Considering the corresponding weight of the evaluation index, Then the weighted gray clustering coefficient $\varphi_{j}(P)$ between the object $P$ to be evaluated and the $j$-th gray class is given as: 


$$
\varphi_{j}(P)=\sum_{i=1}^{n}\left(w_{i} * \psi_{i}^{j}\left(u_{i}(P)\right)\right) \quad 1 \leq j \leq m
$$

According to the above, if the weighted gray clustering coefficient $\varphi_{j}(P)$ between $P$ and the j-th gray class is the maximum, it means that the teaching effect of art major courses of the $P$ belongs to this gray class.

\section{AI-Based Strategies to Improve the Teaching Effect of Art Major Courses}

The above evaluation model was used to evaluate the teaching effect of art majors. It can be found that if the evaluation results cannot meet the requirements, targeted improvements are required. Moreover, with the continuous development of society, the existing teaching models often need to be further improved. To improve the teaching effect of art major courses under the background of artificial intelligence, the author proposed the strategies from the following aspects.

\subsection{Increasing investment and teaching resources in art major courses}

The infrastructure construction of art majors is the basic and necessary condition for the teaching of professional courses. However, compared with other engineering and science majors, art majors require relatively less funding, which will have a certain impact on the construction of art major infrastructure. Therefore, it is necessary to increase the investment in the teaching funds of art majors through various forms such as increasing social investment and strengthening the school art major construction funds. On the basis of increasing the funding for the construction of art majors, various means can be comprehensively used to increase the teaching resources of art major, e.g., introducing high-level art professionals, strengthening the cultivation of young backbone professional talents in art, enhancing the team building ability of art professional teaching, improving the professional quality of art professional teachers, and promoting the infrastructure construction capabilities of teaching software and hardware. This shall provide support for improving the teaching effect of art major courses in the context of the AI.

\subsection{Enhancing the application of intelligent education technology and construction of the teaching platform for art majors}

With the rapid development of modern science and technology, the intelligent education technology is playing an increasingly important role in promoting the quality of education. For this, it is necessary to actively integrate advanced intelligence educational technology into the teaching of art major courses, especially the comprehensive application of network technology, information technology, computer technology, virtual reality technology and multimedia technology. The art major courses not only 
require the teaching of theoretical knowledge, but also the learning of practical content. In this process, the teaching manpower, material resources, financial resources and other factors involved are often more complicated. Thus, based on the comprehensive use of intelligence educational technology, a sound teaching platform for art major courses needs to be established, in order to provide a good support for the intelligentization of art major courses.

\subsection{Improving the teaching management system and the assessment mechanism of art major courses under the background of artificial intelligence}

The teaching management system is the basic guarantee for the smooth implementation of art major teaching. For this, it should be improved in the following aspects: first, improve the rules and regulations related to the teaching of art majors, clarify the rights and obligations of art majors, enhance the sense of responsibility and honor of professional teachers, and especially promote the concept of teaching reform in the context of the AI; second, improve the rules and systems related to the administrative management of the art major, clarify the responsibilities and work content of the administrative body, strengthen the management ability of the teaching manager, promote the sense of responsibility, and enhance the ideological awareness of the in-depth application of artificial intelligence technology in teaching management; third, improve the rules and regulations related to the learning of art majors, clarify the basic training goals and programs for art majors, and standardize the learning of art majors, in order to improve the ability of art majors to independently learn professional knowledge based on artificial intelligence platforms; fourth, improve the assessment mechanism of art majors' teaching effects, and clarify the rewards and punishments, thereby improving the teaching and learning quality of art major course.

\subsection{Promoting the teaching model and the industry-university-research integration in art majors}

In the context of the AI, the teaching model of art major courses needs to be advanced, diverse, and adaptable. In terms of the advanced nature, the teaching model of art majors should closely conform to the development of the times and be able to integrate with advanced intelligent education technology. In terms of the diversity, the teaching models of art majors should not be restricted to a single teaching mode. It needs to be supported by intelligent education technology to achieve effective integration in the aspects of teaching content, methods, means, and forms, etc. The adaptability requires that the teaching model of art majors should have dynamic characteristics of development, and be able to adjust accordingly based on the different needs of social development, especially the needs of social services, so as to enhance the social service awareness and ability of art major courses. At the same time, considering the integration characteristics between the theory and practice of art major course teaching, it is necessary to enhance the ability of industry, university and research integration, and strengthen the coordination and complementarity between industry, academic and 
scientific research topics, thereby effectively improving the teaching effect of art major courses.

\section{Conclusion}

This paper aims to explore the way of improving the teaching effect of art major courses based on AI technology through the combination of theoretical analysis and model calculation. The main conclusions are as follows:

The authors discussed the key factors affecting the teaching effect of art majors under the background of artificial intelligence, and analyzed the specific manifestation, which provides direction for improving the teaching effect of art majors.

The improvement effect of AI technology on the teaching effect of art major courses was analyzed, and the corresponding evaluation analysis model was established, which provides a quantitative analysis basis and tools for the improvement of the teaching effect.

AI-based strategies were proposed to improve the teaching effect of art major courses, which have good reference significance for the improvement of teaching effects in art major teaching.

\section{$8 \quad$ References}

[1] Chassignol, M., Khoroshavin, A., Klimova, A., Bilyatdinova, A. (2018). Artificial Intelligence trends in education: a narrative overview. Procedia Computer Science, 136: 16-24. https://doi.org/10.1016/j.procs.2018.08.233

[2] Winkler-Schwartz, A., Bissonnette, V., Mirchi, N., Ponnudurai, N., Yilmaz, R., Ledwos, N., Del Maestro, R.F. (2019). Artificial intelligence in medical education: best practices using machine learning to assess surgical expertise in virtual reality simulation. Journal of surgical education, 76(6): 1681-1690. https://doi.org/10.1016/j.jsurg.2019.05.015

[3] Sukhbaatar, O., Usagawa, T., Choimaa, L. (2019). An artificial neural network based early prediction of failure-prone students in blended learning course, International Journal of Emerging Technologies in Learning, 14(19), 77-92. https://doi.org/10.3991/ijet.v14 i19.10366

[4] Ahmad, M.F., Ghapar, W.R.G.W.A. (2019). The Era of Artificial Intelligence in Malaysian Higher Education: Impact and Challenges in Tangible Mixed-Reality Learning System toward Self Exploration Education (SEE). Procedia Computer Science, 163: 2-10. https://doi.org/10.1016/j.procs.2019.12.079

[5] Berrezzek, F., Khelil, K., Bouadjila, T. (2019). Efficient wind speed forecasting using discrete wavelet transform and artificial neural networks. Revue intelligence Artificial, 33(6), 447-452. https://doi.org/10.18280/ria.330607

[6] Mostefa, T., Tarak, B., Hachemi, G. (2018). An automatic diagnosis method for an open switch fault in unified power quality conditioner based on artificial neural network. Traitement du Signal, 35(1), 7-21. https://doi.org/10.3166/ts.35.7-21

[7] Zhang D.S., Tan J., Tian H., Wang Z.Z., Guo W.J. (2019). Aquifer parameter inversion by artificial fish swarm algorithm based on quantum theory, Ingenierie des Systems Information, 24(1), 29-33. https://doi.org/10.18280/isi.240103 
[8] Grenfell, J. (2013). Immersive interfaces for art education teaching and learning in virtual and real-world learning environments. Procedia-Social and Behavioral Sciences, 93: 11981211. https://doi.org/10.1016/j.sbspro.2013.10.016

[9] Yu, X. (2019). Research on Improving the Teaching Effect and Realization Path of Art Major Courses by Micro-course. Journal of Zhangzhou University, 36(1): 120-124. https://doi.org/10.13783/j. cnki. cn41-1275/g4.2019. 01.025.

[10] Lin, Y.H. (2019). Analysis of the current situation of the development of art elective courses in Colleges and universities and its teaching optimization strategy. Contemporary Education Research and Teaching Practice, 2019(2): 65-66. https://doi.org/10.16534/j. cnki.cn13-9000/g.2019.0735.

[11] Wan, Y.J. (2020). Application of new media digital image technology in environmental art design teaching, with spatial composition and design as an example. Art and Design, 2020(176): 150-152. https://doi.org/10.16824/j.cnki.issn10082832.2020.01.044.

[12] Chen, H.L. (2017). Research on the implementation effect of micro class teaching in the teaching process of art courses in higher vocational colleges. Art Science and Technology, 2017(12): 33-34. https://doi.org/10.3969/j.issn.1004-9436.2017.12.025

[13] Besgen, A., Kuloglu, N., Fathalizadehalemdari, S. (2015). Teaching/learning strategies through art: Art and basic design education. Procedia-Social and Behavioral Sciences, 182: 428-432. https://doi.org/10.1016/j.sbspro.2015.04.813

[14] Besgen, A. (2015). Teaching/Learning Strategies Through Art: Painting and Basic Design Education. Procedia-Social and Behavioral Sciences, 182: 420-427. https://doi.org/10. 1016/j.sbspro.2015.04.812

[15] Rajasekhar, M., Raju, G.S., Sreenivasulu, Y., Raju, R.S. (2019). Delineation of groundwater potential zones in semi-arid region of Jilledubanderu river basin, Anantapur District, Andhra Pradesh, India using fuzzy logic, AHP and integrated fuzzy-AHP approaches. Hydro Research, 2: 97-108. https://doi.org/10.1016/j.hydres.2019.11.006

[16] Wang, W.X. (2019). Site selection of fire stations in cities based on geographic information system (GIS) and fuzzy analytic hierarchy process (FAHP). Ingénierie des Systèms Information, 24(6), 619-626. https://doi.org/10.18280/isi.240609

[17] Liu, M., Zhang, Q. (2019). Evaluation of student performance with predicted learning curve based on grey models for personalized tutoring. International Journal of Emerging Technologies in Learning, 14(13), 157-171.https://doi.org/10.3991/ijet.v14i13.9880

[18] Jin, X.H., Zheng, J.Y., Geng, X.Y. (2020). Prediction of road traffic accidents based on grey system theory and grey Markov model. International Journal of Safety and Security Engineering, 10(2), 263-268. https://doi.org/10.18280/ijsse.100214

[19] Baffoe, G. (2019). Exploring the utility of Analytic Hierarchy Process (AHP) in ranking livelihood activities for effective and sustainable rural development interventions in developing countries. Evaluation and program planning, 72: 197-204. https://doi.org/10. 1016/j.evalprogplan.2018.10.017

[20] Konstantinos, I., Georgios, T., Garyfalos, A. (2019). A Decision Support System methodology for selecting wind farm installation locations using AHP and TOPSIS: Case study in Eastern Macedonia and Thrace region, Greece. Energy Policy, 132: 232-246. https://doi.org/10.1016/j.enpol.2019.05.020

[21] Kumar, R., Padhi, S.S., Sarkar, A. (2019). Supplier selection of an Indian heavy locomotive manufacturer: An integrated approach using Taguchi loss function, TOPSIS, and AHP. IIMB Management Review, 31(1): 78-90. https://doi.org/10.1016/j.iimb.2018.08. $\underline{008}$ 
[22] Karakoç, Ö., Es, H.A., Firat, S.Ü. (2019). Evaluation of the development level of provinces by grey cluster analysis. Procedia Computer Science, 158: 135-144. https://doi.org/10. 1016/j.procs.2019.09.036

[23] Delgado, A., Romero, I. (2016). Environmental conflict analysis using an integrated grey clustering and entropy-weight method: A case study of a mining project in Peru. Environmental Modelling \& Software, 77: 108-121.https://doi.org/10.1016/j.envsoft.2015.12.011

[24] Shang, H. (2020). Model and algorithms of enterprise informatization software selection based on grey relational analysis. Ingénierie des System's Information, 25(1), 107-112. https://doi.org/10.18280/isi.250114

[25] Rajesh, R. (2018). Measuring the barriers to resilience in manufacturing supply chains using Grey Clustering and VIKOR approaches. Measurement, 126: 259-273. https://doi.org/10.1016/j.measurement.2018.05.043.

\section{$9 \quad$ Author}

Ran Yang is member of the art criticism, (Art Theory and Management Department) Sichuan conservatory of Music. she is an Artist. Her research focuses on the diversity and innovation of public art education in the era of artificial intelligence. Her video is collected by A4 Arts Museum. Email: yangjinhan000@163.com

Article submitted 2020-09-02. Resubmitted 2020-09-29. Final acceptance 2020-09-30. Final version published as submitted by the authors. 